\title{
The Effect of Biochar Application on Nutrient Availability of Soil Planted with MR219
}

Nur Firdaus Abdul $\mathbf{R}^{*}$ and Nur Syahirah Abdul $\mathbf{R}$

Faculty of Plantation and Agrotechnology, Universiti Teknologi MARA, Melaka, Malaysia

\begin{abstract}
This study aims to determine the effect of biochars on the soil $\mathrm{pH}$, nutrient content in soil and the growth performance in terms of height of paddy and number of tiller in a field experiment. Biochars as a new soil amendment has a potential in controlling the fate of trace elements in the soil system. However, the production of biochar from different types of biomass resulted in variable biochars properties which have an influence on trace elements availability in soil. Both biochars type was tested at equal rates respectively. The results detailing the nutrient content and growth performance of paddy showed that the application of both RH and EFB improve biomass production. The results show that the addition of EFB biochar to soil has a positive effect in growth performance and nutrient content. However, after running the statistical analysis on data, it shows that there is no significant difference between the treatments either in soil $\mathrm{pH}$, nutrient content, plant height and the number of tiller on paddy $(P>0.05)$.
\end{abstract}

\section{Introduction}

Biochar is plant based materials that has been charred by a process called pyrolysis, where there is no or less oxygen. It is rich in carbon elements. Biochar is referred to the plant biomass derived materials that includes chars and charcoal while excluding fossil fuel products [1]. The function of biochars are used as a soil amendment which enhances plant growth and nutrient use efficiency, improved holding capacity of nutrients such as nitrogen, calcium, phosphorus and has higher $\mathrm{pH}$ and higher moisture-holding capacity to the soils. Biochar is usually produced from plant residue such as paddy husk, corn stalk, rubber pod and oil palm's empty fruit bunches (EFB). Different types of plant residues require different temperature in order to turn into biochar. MR219 is a variety of rice that is widely planted in Malaysia due to its high yield potential (10.75 tonne/ha), shorter life cycle (105 to 111 days) and is good for consumption [2].

\section{Types of soil}

Soil of silty clay loam can be classified as one properties of soil organic matter. Some of the physical properties of silty clay loam have been proposed as indicators of soil quality. Long term sustainable agriculture based on the maintenance since its level generally lead to decreased crop productivity. The continuous cultivation in soil silty clay loam in most irrigated lands has resulted in the decline of soil physical condition. There are some of the properties of these soil which are the soil structure is strongly related to organic matter because it's binds mineral particles into aggregates and reduces the susceptibility of soil to erosion. However in terms of the quality of soil, silty clay loam based on its soil structure on water sized stable shows that the soil is highly enriched and most labile fraction [3]. Usually in extremely low $\mathrm{pH}$ condition, the soil is subject to drought and with limited nutrients and poor drainage.

Application of fertilizers and biochars, however, can increase soil $\mathrm{pH}$ and also increased nutrient availability to plants with biomass of carbon (C) increase especially in low $\mathrm{pH}$ soil [4]. Application of biochars can improve soil's physiochemical properties in terms of water holding capacity (WHC), increase the activity of microbes and available nutrient. Suggested that with the addition of biochars to the silty clay loam, it can alter the soil's properties such as $\mathrm{pH}, \mathrm{WHC}, \mathrm{CEC}$ and plant nutrient [5].

\section{Objectives}

- To determine the content of biochars in term of nutrient.

- $\quad$ To determine the effect of difference biochars used on MR219 rice growth.

\section{Methodology}

There are three treatments applied to the MR219 paddy - EFB biochar, rice husk biochar and conventional NPK fertiliser as control planted in silty clay loam soil. Treatment was applied on $3^{\text {rd }}, 7^{\text {th }}$ and $10^{\text {th }}$ weeks. Data on paddy growth were collected on weekly basis and nutrient content in soil was tested the week following application of treatment. The nutrient content of biochar was tested using dry ashing method while nutrient content was tested using acid digestion method. Samples from both tests was analysed using the Perkin Elmer's Inductively Coupled Plasma Optical Emission Spectrometer (ICP-OES). All data and ICP's result are further analysed using Minitab software (Figure 1).

\section{Results and Discussion}

Figure 1 above presents the nutrient content in Empty fruit bunch biochars (EFBB) and rice husk biochars (RHB) used for the experiment. The EFBB were high in every element compared to the RHB which are lower. The EFBB are quite high in $\mathrm{K}$ and had more $\mathrm{C}$ than $\mathrm{P}$ and $\mathrm{Mg}$. Figure above shows $\mathrm{Ca}$ and $\mathrm{Mg}$ in $\mathrm{RH}$ is low compared to in EFB biochar. However the availability nutrient on that element is related to the $\mathrm{pH}$ value. Since somehow the $\mathrm{pH}$ of $\mathrm{RH}$ is 4.8 something it affects the amount of $\mathrm{Ca}$ and $\mathrm{Mg}$ because $\mathrm{pH}$ of $\mathrm{RH}$ is less than $5, \mathrm{Ca}$ and $\mathrm{Mg}$

*Corresponding author: Nur Firdaus Abdul R, Faculty of Plantation and Agrotechnology, Universiti Teknologi MARA, Melaka, Malaysia, Tel: 60124950157 ; Fax: 6062645232; E-mail: nurfirdaus@melaka.uitm.edu.my

Received March 06, 2017; Accepted April 22, 2017; Published April 29, 2017

Citation: Abdul RNF, Abdul RNS (2017) The Effect of Biochar Application on Nutrient Availability of Soil Planted with MR219. J Microb Biochem Technol 9:583586. doi: 10.4172/1948-5948.1000345

Copyright: () 2017 Abdul RNF, et al. This is an open-access article distributed under the terms of the Creative Commons Attribution License, which permits unrestricted use, distribution, and reproduction in any medium, provided the original author and source are credited. 


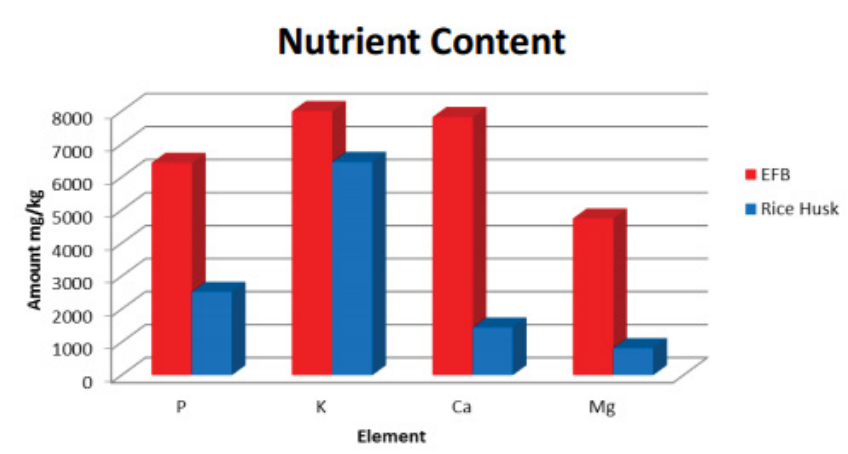

Figure 1: Nutrient content on EFBB and RHB.

is generally low amount. However the high content of $\mathrm{K}$ and $\mathrm{Ca}$ is expected to benefit from application of EFBB with a good temperature of biochars the application for both treatment to MR219 was applied with $18 \mathrm{~g}$ of biochars for total application of 3 times within week 3 to week 9 , and the timeline of application are referred from manuring programme schedule for participating farmers [6,7]. In terms of plant height, application of EFBB and RHB to the plant were not significant $(\mathrm{P}=0.432)$ and the effect of plant growth also not significant even though the height and number of tiller plant showed an improvement from week 3 to week 10. The increase in soil nutrients and an improvement in plant due to the biochars application are consistent with the work of where the application of biochars had increase the content of nitrate $\left(\mathrm{NO}_{3}{ }^{-}\right)$especially at tillering stage [8]. Plus, the increased in nutrients of biochars can be directly relate to the increases in soil $\mathrm{pH}$ recorded for the treatment (Table 1).

In fact every parameter's reading increased with the addition of biochars. Based on the physical properties of biochars, Table 1 shows the different pyrolysis temperatures. The biochars that were applied on plants with $550^{\circ} \mathrm{C}$, The temperature were choose because it is shows the best result were on $500^{\circ} \mathrm{C}$ for $\mathrm{EFB}$ and $\mathrm{RH}$ in terms of nutrients content as shown in table below. The variability of the nutrients in the biochars with increasing temperature is due to their volatility and effect of pyrolysis temperature on both composition and chemical structure of biochars. Besides the concentration of the nutrients in the biochar also depend on the process of partial devolatilization of the nutrients at elevated temperatures [9].

There is no significant difference between application of EFB and rice husk biochar in terms of plants height as well as number of tiller. According to usage of biochar alone without the combination of urea fertilizer cannot gave much effect to growth performance of paddy (Figure 2).

In terms of crop production, the application of biochars generally, should be beneficial to the plant height on the Figure 2. The effects of biochars amendments on rice growth are shown in figure above. Overall, biochars application had positive effects on the paddy growth. EFB biochars application significantly increased height and number of tillers in few successive weeks. In weeks 5 the paddy treated with EFB amendments increased from $52.25 \mathrm{~cm}$ and 5.25 numbers of tillers to $94.75 \mathrm{~cm}$ in height and 46 tillers, respectively. In particular, in comparison with the corresponding controls, chemical fertilizer (NPK) showed a smaller gap between EFB either in height or number of tillers.

However, same goes to the rice husk that showed a poor response on effect of biochars which are from $37.25 \mathrm{~cm}$ and 4 to $93 \mathrm{~cm}$ and

\begin{tabular}{|c|c|c|c|c|c|c|}
\hline \multirow{2}{*}{$\begin{array}{l}\text { Chemical } \\
\text { property }\end{array}$} & \multicolumn{3}{|c|}{ Rice husk } & \multicolumn{3}{|c|}{ Empty fruit bunch } \\
\hline & $350^{\circ} \mathrm{C}$ & $500^{\circ} \mathrm{C}$ & $650^{\circ} \mathrm{C}$ & $350^{\circ} \mathrm{C}$ & $500^{\circ} \mathrm{C}$ & $650^{\circ} \mathrm{C}$ \\
\hline pH & 6.66 & 7.99 & 8.88 & 8.31 & 9.89 & 10.29 \\
\hline$E C\left(\mathrm{mS} \mathrm{cm}^{-1}\right)$ & 0.52 & 0.92 & 1.11 & 2.87 & 5.36 & 6.75 \\
\hline CEC (cmot.kg-1) & 10.80 & 9.39 & 8.35 & 21.50 & 14.60 & 12.03 \\
\hline \multicolumn{7}{|c|}{ Elemental analysis (wt\%) } \\
\hline $\mathbf{C}$ & 47.99 & 44.64 & 42.95 & 61.96 & 65.88 & 64.53 \\
\hline $\mathbf{N}$ & 0.73 & 0.77 & 0.53 & 1.08 & 0.87 & 0.72 \\
\hline S & 0.03 & 0.02 & 0.02 & 0.02 & 0.01 & 0.02 \\
\hline H & 5.27 & 3.96 & 2.11 & 7.67 & 4.23 & 3.10 \\
\hline $\mathbf{O}^{\mathrm{a}}$ & 46.01 & 50.63 & 54.41 & 29.29 & 29.02 & 31.65 \\
\hline $\mathrm{H} / \mathrm{C}$ molar ratio & 1.32 & 1.06 & 0.59 & 1.49 & 0.77 & 0.58 \\
\hline O/C molar ratio & 0.72 & 0.85 & 0.95 & 0.35 & 0.33 & 0.37 \\
\hline $\mathrm{Al}$ & 0.011 & 0.018 & 0.019 & 0.045 & 0.065 & 0.060 \\
\hline $\mathrm{Ca}$ & 0.124 & 0.154 & 0.189 & 0.381 & 0.544 & 0.561 \\
\hline $\mathrm{Fe}$ & 0.039 & 0.154 & 0.049 & 0.096 & 0.304 & 0.15 \\
\hline Mg & 0.095 & 0.135 & 0.175 & 0.26 & 0.396 & 0.415 \\
\hline Si & 0.014 & 0.04 & 0.015 & 0.033 & 0.036 & 0.017 \\
\hline $\mathrm{Na}$ & 0.061 & 0.066 & 0.079 & 0.046 & 0.056 & 0.058 \\
\hline $\mathbf{P}$ & 0.074 & 0.142 & 0.196 & 0.104 & 0.151 & 0.190 \\
\hline $\mathrm{K}$ & 0.735 & 1.120 & 1.195 & 4.175 & 5.600 & 6.550 \\
\hline
\end{tabular}

Table 1: The chemical properties of rice husk and empty fruit bunch biochars produced different pyrolysis temperatures.

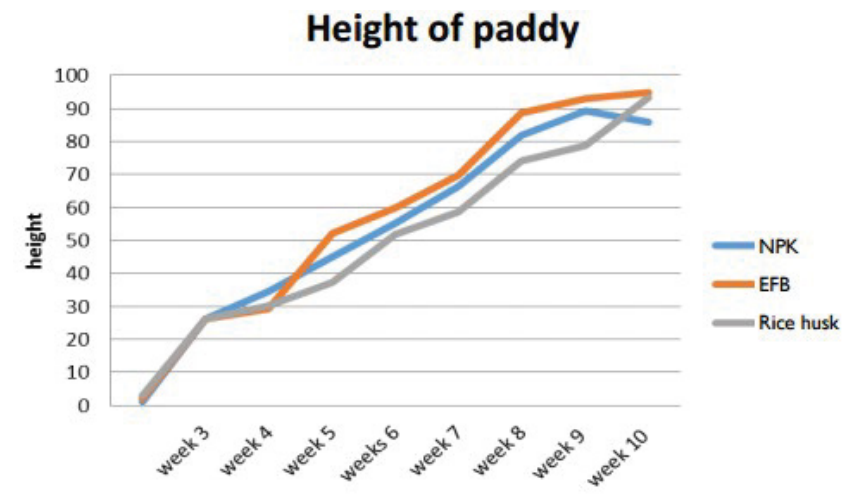

Figure 2: Height of paddy.

40. Based on the three treatments, EFB give the result in terms of the plant height compared to the other two treatments. The amount of treatments are applied with the same amount per pail are based on journal which are 0.9 gram for NPK and 18 gram for both biochars. A statistically notable rise in the rice productivity are compared with its control treatment shown that the height of paddy and the number of tillers has no significance difference $(\mathrm{P}=0.432)$ on the application of the treatments but it had a significantly positive effect on the height and number of tiller. The positive growth responses were partly attributed to the nutrients directly supplied by the biochars and NPK.

However, the growth performance differed with biochars types. Rice husk usually had a high $\mathrm{pH}$, therefore it is reasonable that the soil treated with rice husk biochars also had a high $\mathrm{pH}$ since it has high CEC value, $P$ and $K$ content. This result indicated that acidic soil can be treated with rice husk biochars can used as substitute application for lime materials in order to improve the $\mathrm{pH}$ soil (Figure 3).

The Figure 3 above shows the average of nutrient content before and after treatment of biochars. It indicates the amount of every element which is $\mathrm{P}, \mathrm{K}, \mathrm{Ca}$ and $\mathrm{Mg}$ before treatment is lower than after treatment. 


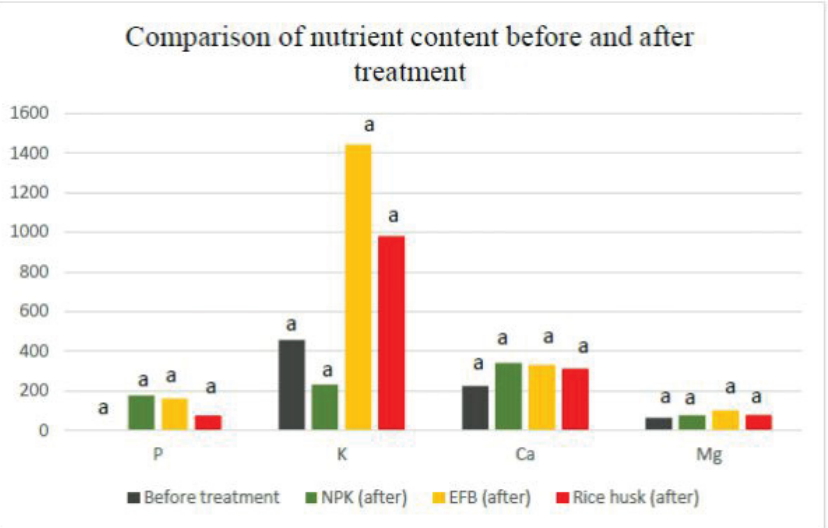

Figure 3: The average of nutrient content before and after treatment in soil.

Referred to the graph, the result present in the EFB treatment shows a most higher on the element especially in $\mathrm{K}$ and $\mathrm{Mg}$. However the test statistical analysis shows that there is no significant different of nutrient content between before and after treatment. The element of $\mathrm{K}$ assist in regulating the plants used water by controlling the opening and closing of leaf stomata, where water release to cool the plant while $\mathrm{Mg}$ help in major constituent of the chlorophyll molecule, and it is therefore actively involved in photosynthesis. K element is essential for growth performance and reproductive activities of plant. Stated that the potassium levels remain high with increased biochar levels. So that this can implies by addition of biochars will greatly increase K levels in soil [10].

Nutrient availability in soil before treatment is lower due to low soil $\mathrm{pH}$ of silty clay loam. Application of fertilizers and biochar, however, can increase soil $\mathrm{pH}$ and also increased nutrient availability to plants with biomass of carbon (C) increase especially in low $\mathrm{pH}$ soil. This makes sense since biochar is shown to increase nutrient levels, such as magnesium. As shown in Figure 3, magnesium levels increase as biochar is added, so the percent of exchangeable magnesium naturally increases relative to the CEC.

For $\mathrm{P}$ the amount of $\mathrm{P}$ before treatment is lower compare to after treatment. The amount of $\mathrm{P}$ in NPK after treatment is the highest compare to the other treatment. However after running the statistical test there is no significant difference between each treatment $(\mathrm{P}=0.477)$. Referred the graph 3 the content of NPK in element P is higher compared to K element. This is due to K element is easily leached in soil compared to $\mathrm{P}$ element. There a few studies have reported a relatively low $\mathrm{P}$ leaching amount in soils, mainly because of low permeability.

For $\mathrm{K}$ the amount of $\mathrm{K}$ before treatment is lower compare to mount of $\mathrm{K}$ after treatment of EFB and Rice husk. While P before treatment is higher compare to the NPK after treatment. The function of K is known to be an enzyme that promotes metabolism in plant. In plant $\mathrm{K}$ is needed in photosynthesis and synthesis of proteins, plants lacking $\mathrm{K}$ will have slow and stunted growth. While deficiency of $\mathrm{P}$ in soil affect the plant growth, $\mathrm{P}$ technically assists in the activation of many growth-related enzymes in plants, and it therefore aids in proper plant growth. From the result height and the number of tiller in paddy shows an increased. Hence, it can be said that with the increased of K, the growth of paddy also increased. However from the test statistical analysis shows that there is no significant difference between each treatment $(\mathrm{P}=0.119)$.

For $\mathrm{Ca}$ the amount of $\mathrm{Ca}$ before treatment is lower compared to the value of NPK, EFB and $\mathrm{RH}$ after treatment. After running the statistical test the result shows there is no significant difference between each treatment $(\mathrm{P}=0.698)$. Stated that with the addition of biochars, calcium becomes increasingly available in the soil as the negatively charged surface of biochars attracts the positively charged ions such as $\mathrm{Ca}$ and make it available to plants. However, calcium in all soil treatments is still considered low for soil. $\mathrm{Ca}$ is an activator of several enzymes systems in protein and carbohydrate transfer. Besides $\mathrm{Ca}$ has a major role in the formation of the cell wall membrane in plant cell.

For $\mathrm{Mg}$ the amount of $\mathrm{Mg}$ before treatment is lower compared to the value of NPK, EFB and RH after treatment. However from test statistical analysis shows that there is no significant difference between each treatment $(\mathrm{P}=0.765) . \mathrm{Mg}$ is a major constituent of the chlorophyll molecule; therefore $\mathrm{K}$ is actively involved in the photosynthesis activity and also helps in stabilizing the structure of nucleic acids. According to when biochars is added along with compost, the exchangeable $\mathrm{Mg}$ was increases.

\section{Conclusion and Recommendation}

From the result we can estimate that biochars from EFB is better than RH in term of its nutrient content. But from the ANOVA test, it showed that there is no significant difference between both treatment in term of its nutrient content and plant growth (plant height and tiller). So we can choose to apply NPK fertilizer, EFB or RH biochars to the field since it end up with the same results. For future study, rate of biochars and NPK fertilizer application need to be increased and varied so that a more significant result can be achieved from the treatments. To the farmers that are concerned towards the environment, the use EFB or RH biochars are recommended. In term of cost, both EFB and RH biochars come as cheaper alternatives to the conventional practices of using the chemical fertilizer. Plus the use of biochars can also reduce toxicity to the soil.

\section{Acknowledgement}

I would firstly like to acknowledge and thank my supervisor, Madam Nur Firdaus Binti Abdul Rashid, for her contribution and support to complete my Final Year Project for one semester (Sept-Jan 2016). I would also like to thanks to laboratory assistant for their cooperation. I would like to thank my family for their love and support, course mate for their help from the beginning till the end of my project work. Last but not least, thanks to Universiti Teknologi Mara (UiTM) that provides me the facilities and instrument in order to complete my Final Year Project.

\section{References}

1. Lehmann J, Joseph S (2009) Biochar for environmental management. Science and Technology, pp: 1-4.

2. Parvis $F$, Kharidah M, Aminah A, Wickneswari R (2012) Proximate nutritional composition and antioxidant properties of Oryza rufipogon. A wild rice collected from Malaysia compared to cultivated rice. Australian Journal of Crop Science, p: 6.

3. Bhattacharyya R, Chandra S, Singh RD (2007) Long-term manure application effects on properties of a silty clay loam soil under irrigated wheat-soybean rotation. Soil Tillage Res 94: 386-396.

4. Andrenelli (2015) Field application of pelletized biochar: Short term effect on the hydrological properties of a silty clay loam soil. Agric Water Manag 163: 190-196.

5. Warnock DD, Lehmann J, Kuyper TW, Rillig MC (2007) Mycorrhizal responses to biochar in soil - concepts and mechanisms. Plant Soil 300: 9-20.

6. Jung WK (2012) Rice yield responses to biochar application under different water managements practices. Journal Soil Science Fertility 45: 16-19.

7. Liew (2012) Effect of foliar applied copper and boron on fungal disease and rice yield on cultivar MR 219. Pertanika J Trop Agric Sci 35: 339-349. 
Citation: Abdul RNF, Abdul RNS (2017) The Effect of Biochar Application on Nutrient Availability of Soil Planted with MR219. J Microb Biochem Technol 9:583-586. doi: 10.4172/1948-5948.1000345

8. Dong D, Feng Q, Mcgrouther K, Yang M (2015) Effect of biochar amendment on rice growth and nitrogen retention in a waterlogged paddy field. Journal Soil Sediments 15: 153-162.

9. Claoston N (2014) Effects of pyrolysis temperature on the physicochemical properties of empty fruit bunch and rice husk biochars. Waste Manag Res 32 331-339.

10. Nicole CE (2013) Soil nutrient availability properties of biochar. 